\title{
Peripheral T- cell lymphoma not otherwise specified - a patient with extranodal pancreatic involvement detected by FDG PET/CT: a case report and review of the literature
}

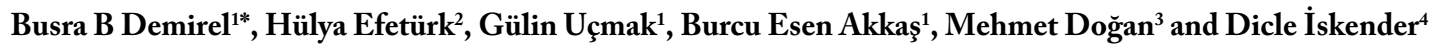 \\ ${ }^{1}$ SBU Ankara Oncology Research and Training Hospital, Department of Nuclear Medicine, Ankara, Turkey \\ ${ }^{2}$ Dr. Burhan Nalbantoğlu Nicosia State Hospital, Nicosia, Turkish Republic of Northern Cyprus \\ ${ }^{3}$ SBU Ankara Oncology Research and Training Hospital, Department of Clinical Pathology, Ankara, Turkey \\ ${ }^{4}$ SBU Ankara Oncology Research and Training Hospital, Department of Hematology, Ankara, Turkey
}

\begin{abstract}
Peripheral T-cell lymphomas, (PTCL) are rare and heterogeneous group of lymphoid malignancies arising from mature or precursor T-cells. The most common sites of extranodal involvement in peripheral T-cell lymphomas are the spleen, liver, skin, lungs and subcutaneous tissue. The frequency of primary pancreatic involvement has been reported as $2.2 \%$ and secondary pancreatic involvement $0.2-2 \%$ in NHL patients. FDG PET/CT has been found to efficiently identify more sites of extranodal disease compared to contrast enhanced CT scan. The sensitivity and specificity of PET/CT in detecting extranodal lymphoma is $88 \%$ and $100 \%$ respectively. To our knowledge, no cases with pancreatic involvement of peripheral T-cell lymphoma detected by PET/CT have been reported in the literature.
\end{abstract}

\section{Introduction}

Peripheral T-cell lymphomas (PTCL) are rare and heterogeneous group of lymphoid malignancies arising from mature or precursor T-cells. PTCLs make up approximately $15-20 \%$ of all Non-hodgkin lymphomas and has a varying incidence around the world $[1,2]$. The latest and most widely used classification of PTCLs is by the World Health Organization (WHO) and divides into many categories and subtypes. The classification mainly consists of 3 large groups: Anaplastic large cell lymphoma, Angioimmunoblastic T-cell lymphoma (AITL) and subtypes which are no further classifiable in the WHO classification are peripheral T-cell lymphoma-not otherwise specified (PTCL-NOS). PTCLs can also be examined depending on where they primarily derive from and their typical presentations; the cutaneous types are usually indolent while the nodal and extranodal presenting types usually exhibit aggressive behavior [1,2].

The known most frequently diagnosed subgroup of PTCL is PTCLNOS by $25 \%$ and is a heterogeneous highly aggressive lymphoma known to have a poor prognosis [2]. PTCL-NOS typically occurs in adults (median age 55-60 years), with a higher prevalence in males $[2,3]$. Approximately $70-80 \%$ of patients present with disseminated disease (stage III or IV disease) and often have B symptoms, generalized lymphadenopathy, bone marrow infiltration and extranodal involvement (skin and gastrointestinal tract being the most commonly affected sites), with high or high-intermediate International Prognostic Index (IPI) score in 50-70\% cases [3]. According to one of the most extensive studies on PTCL-NOS patients to date, by the International Peripheral T-cell Lymphoma Project, the most frequent presentation of PTCL-NOS is nodal and extranodal disease by $49 \%$, only nodal disease is present in $38 \%$ and most least presentation type is extranodal by $13 \%[1,2]$. The most common reported extranodal sites were the spleen $(24 \%)$, liver (17\%), skin (16\%), lungs $(8 \%)$ and subcutaneous tissue (6\%) [2]. The frequency of primary pancreatic involvement has been reported as $2.2 \%$ and secondary pancreatic involvement $0.2-2 \%$ in NHL patients. A few cases of pancreatic involvement of NHL have been reported in the literature and to our knowledge, none have been reported as peripheral T-cell lymphoma [4-6].

\section{Case report}

A 47-year-old female was admitted to hospital with complaint of abdominal pain, nausea and left lower abdominal sensitivity on physical examination. Tests revealed a mass in the small intestine and immediately underwent laparoscopic segmental intestinal resection. Review of the resected mass was carried out by experienced pathologists and was consistent with peripheral T-cell lymphoma not otherwise specified (PTCL NOS). Microscopic evaluation showed residual lymphoid follicules and small-medium sized atypical lymphocytes with clear cytoplasms and irregular hyperchromatic nuclei. Immunohistochemistry demonstrated lymphocyte markers (CD3, CD43, CD8 and CD56) strongly positive, and a typical lymphocyte marker such as CD138 and MUM-1 were positive. The Ki-67 proliferation index was $70 \%$. Bone marrow biopsy did not show involvement of lymphoma. Standard staging studies including computed tomography (CT) of the neck, chest, upper and lower abdomen showed no pathological findings. After receiving six cycles of $\mathrm{CHOP}$

${ }^{\star}$ Correspondence to: Busra B Demirel M.D, Ankara Oncology Research and Training Hospital, Department of Nuclear Medicine, Ankara, Turkey, Tel: +90 533 2245294; Fax: +90 312 3363067; E-mail: demirelbbusra@hotmail.com

Key words: Peripheral T-cell lymphoma, pancreatic involvement, FDG PET/CT

Received: March 05, 2018; Accepted: March 27, 2018; Published: March 30, 2018 
(cyclophosphamide, vincristine, doxorubicin and prednisone) regimen, consolidation with autologous stem cell transplantation (ASCT) was planned. Prior to ASCT, the patient was referred for a whole body 18-FDG PET/CT to assess response to treatment. 18-FDG PET/CT revealed a focal increase of uptake of FDG (standardized uptake value of 6.10) in the corpus of the pancreas approximately $1.5 \mathrm{~cm}$ in diameter which showed somewhat amount of increase in activity in dual-phase screening while no distinctive lesion was detectable on unenhanced CT (Figure 1). A pancreatic lesion had not been shown by the diagnostic enhanced CT prior to and during chemotherapy. Correlative Magnetic Resonance Imaging (MRI) study, done after the PET/CT, supported the PET/CT findings. It concluded the lesion as being a hypointense pancreatic mass approximately $1.6 \mathrm{~cm}$ in diameter in concordance with lymphomatous pancreatic involvement. An ultrasound guided tru-cut biopsy was deemed non-diagnostic, thus, an intraoperatively performed excisional biopsy was carried out identifying the pancreatic lesion as atypical $\mathrm{T}$ cell lymphocyte infiltration. Histopathological

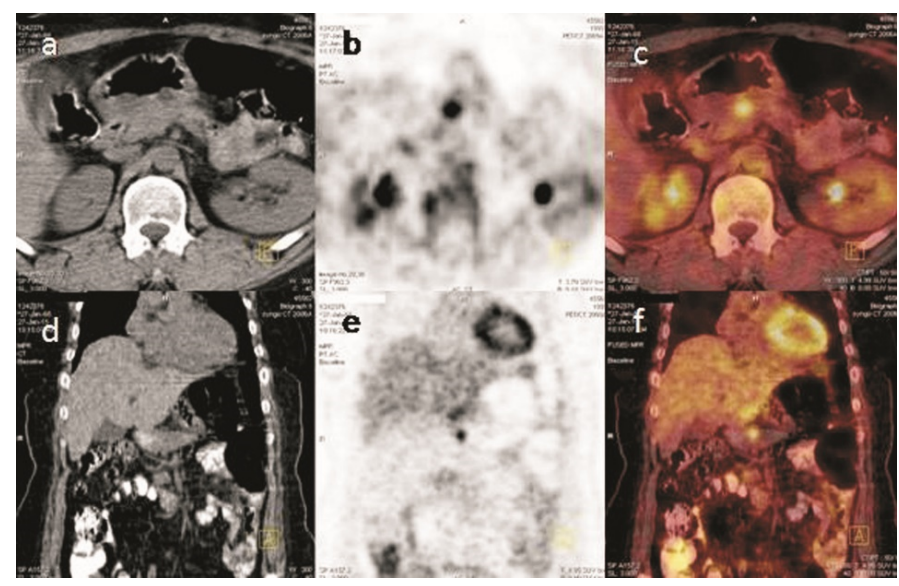

Figure 1. Transaxial and coronal cross-sectional 18-FDG PET/CT images of the patient.

(a) and (d) are tomographic cross sections of the abdomen show the pancreas with no prominent lesion.

(b) and (e) is a focal uptake of FDG is observed in the pancreas, correctly anatomicaly localised by the CT.

(c) and (f) are the fusion images of PET and CT are shown.

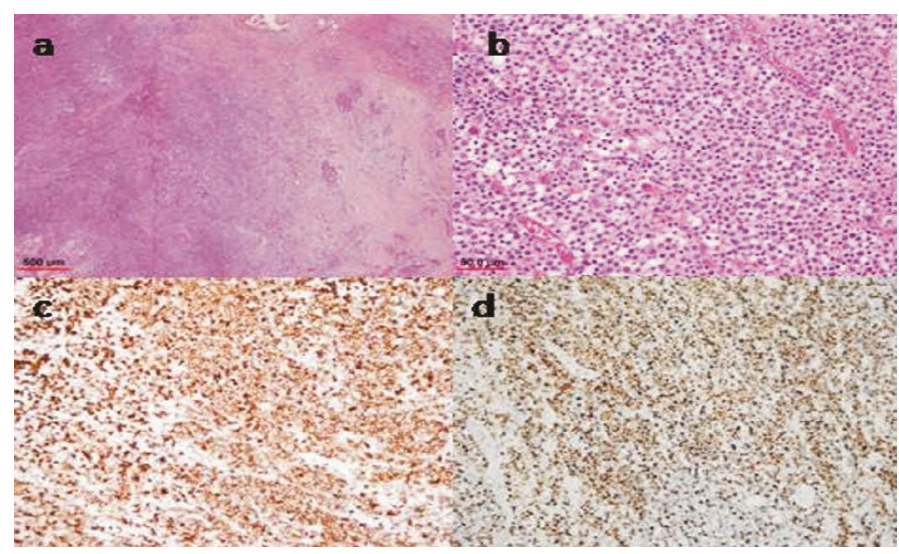

Figure 2. Microscopic evaluation of tru-cut biopsy of pancreas. (a) (Hematoxylin-eosin, original magnification $\mathrm{x} 40$ ) Lymphoid cell infiltration can be seen on the left side of the image, and residual fibrotic changes and evidence of inflammation on the right side. (b) (Hematoxylin-eosin, original magnification x400) Higher magnification shows medium sized, atypical lymphoid cells with pale eosinophilic cytoplasm. (c) (original magnification x200) Atypical lymphoid cells were diffusely stained positive with CD8. (d) (Ki marking, original magnification $\mathrm{x} 200$ ) The neoplastic cells were seen to have a high $\mathrm{Ki}-67$ proliferation index $(50 \%)$. interpretation of the lesion was done by different expert pathologists. Immunohistochemistry showed positive staining for CD2, CD3, CD8 and CD7, while CD4, CD20, CD10, CD30 and CD23 were negative. The Ki-67 was $50 \%$ (Figure 2). The currently stage IVA PTCL patient with an IPI score 3, was evaluated as having progressive disease. The PET/CT evaluation resulted in a change in therapy management and the patient is currently receiving salvage chemotherapy.

\section{Discussion}

T-cell lymphomas contribute to approximately $10-15 \%$ of all lymphoid malignancies [2]. It is usually staged by the Ann-Arbor staging system and its most commonly used prognostic index is the IPI score. They most frequently present at an advanced stage, and especially the aggressive types have a short survival [3]. Current standard chemotherapy regimens such as CHOP, has insufficient efficacies, and no definitive curative therapy has been shown to be successful in treating PTCL-NOS $[7,8]$. According to the International T-cell Lymphoma Study, the overall survival (OS) and failure-free survival (FFS) with PTCL-NOS at 10 to 15 years is 10\% [9].

It is known that the use of PET/CT in HL and B-cell lymphomas has been demonstrated extensively in staging, restaging and therapy response whereas the use of PET/CT in T-cell lymphomas is still controversial. Recent studies suggest that PET/CT can be used in a similar manner to aggressive B-cell lymphomas [10,11]. According to a meta-analysis done by Zhou et al., based on the systematic review of eight studies, the pooled sensitivity and specificity of PET/CT in the diagnosis and staging of NK/T-cell lymphoma were $95 \%$ and $40 \%$, and $98 \%$ and $99 \%$ respectively. The results demonstrated that PET/CT has high sensitivity and specificity in detecting the NK/T-cell lymphoma related lesions [12]. T-cell lymphomas are generally FDG avid, although avidity varies according to $\mathrm{T}$ cell subtype $[11,13]$.

F18-FDG PET/CT may provide prognostic information and a negative interim or post-therapy FDG PET/CT may predict a higher progression free survival (PFS) rate as shown in recent studies $[12,13]$. Also, interim PET/CT findings can be used in therapy management [13].

The most common sites of extranodal involvement in peripheral T-cell lymphomas are the spleen, liver, skin, lungs and subcutaneous tissue [14]. Pancreatic involvement by NHL is more commonly the result of local extension or secondary involvement by widespread disease as opposed to development of a primary lesion. Primary pancreatic lymphoma accounts for less than $0.5 \%$ of all pancreatic malignancies and $1 \%$ of extranodal lymphomas. Secondary involvement of the pancreas by lymphoma is reported to occur in $5 \%$ to $30 \%$ of all lymphomas [15].

The imaging characteristics of extranodal involvement can be subtle or even absent in conventional computed tomography. Imaging the tumor metabolism with 18-FDG PET/CT has enabled and improved the identification of extranodal manifestations, even when CT has demonstrated no lesions [16]. FDG PET/CT has been found to efficiently identify more sites of extranodal disease compared to contrast enhanced CT scan in $50 \%$ of patients in a study [13]. In our case, the pancreatic lesion detected on FDG PET/CT had not been identified by conventional radiological studies done prior to and during treatment. The advantages of FDG PET/CT for staging and restaging of both HL and NHL is mostly attributed to the detection of FDG avid, normal sized lymph nodes and of extranodal sites that were previously missed out on CT [14]. The sensitivity and specificity of PET/CT in detecting 
extranodal lymphoma is $88 \%$ and $100 \%$ respectively while is has been found to be $50 \%$ and $90 \%$ respectively in contrast enhanced CT [16].

The treatment strategies of NK/T cell lymphoma patients depend on the stage of disease [12]. Our patient who didn't have a baseline PET/ CT, no other known nodal/extranodal site except the intestinal mass, started standard chemotherapy protocol at stage IE. The response to treatment evaluation PET/CT upstaged the patient and changed the treatment plan by detecting the pancreatic involvement. The usefulness of PET/CT in identifying and following extranodal disease in PTCL has also been shown in various studies $[6,16,17]$.

In our case we can easily say that the PET/CT performed also served as an evaluation tool for pre- stem cell transplantation evaluation and changed the course of treatment plan by not allowing ASCT thus inhibiting unnecessary intervention, potential morbidity, and supporting cost-effectivity. Our case demonstrated the role of PET/CT in treatment response, locating extranodal sites, restaging, pre ASCT evaluation, and monitoring the treatment plan. Accurate staging/ knowledge of extent of disease may be useful in baseline evaluation, follow-up and response assessment thus playing a decisive role in the prognosis and treatment strategy of NK/T-cell lymphomas. Future advances in assessing and treating this aggressive, heterogeneous group of lymphomas will not be possible without the use of a guiding tool, the PET/CT.

\section{References}

1. Li YJ, Li ZM, Xia XY, Huang HQ, Xia ZJ, et al. (2013) Prognostic value of interim and posttherapy $18 \mathrm{~F}-\mathrm{FDG} \mathrm{PET} / \mathrm{CT}$ in patients with mature T-cell and natural killer cell lymphomas. J Nucl Med 54: 507-515. [Crossref]

2. Armitage JO (2017) The aggressive peripheral T-cell lymphomas: 2017. Am J Hematol 92: 706-715. [Crossref]

3. Savage KJ, Ferreri AJ, Zinzani PL, Pileri SA (2011) Peripheral T-cell lymphoma-not otherwise specified. Crit Rev Oncol Hematol 79: 321-329. [Crossref]

4. Kamaleshwaran KK, Natarajan S, Mohanan V, Shinto AS (2015) 18F-FDG PET/ $\mathrm{CT}$ in Staging and Response Evaluation of Rare Case of Non-Hodgkin's Lymphoma Involving Pericardium, Kidney and Pancreas. Int J Nuclear Med Res 2: 19-21.
5. Saif MW, Khubchandani S, Walczak M (2007) Secondary pancreatic involvement by a diffuse large B-cell lymphoma presenting as acute pancreatitis. World J Gastroenterol 13: 4909-4911. [Crossref]

6. Puranik AD, Agrawal A, Purandare NC, Shah S, Rangarajan V (2013) Four rare extranodal sites seen on FDG PET/CT in a single patient of disseminated lymphoma. Indian J Med Paediatr Oncol 34: 101-103. [Crossref]

7. Prochazka V, Faber E, Raida L, Vondrakova J, Kucerova L, et al. (2009) Prolonged survival of patients with peripheral T-cell lymphoma after first-line intensive sequential chemotherapy with autologous stem cell transplantation. Biomed Pap 153: 63-66. [Crossref]

8. Lage LA, Cabral TC, Costa Rde O, Gonçalves Mde C, Levy D, et al. (2015) Primary nodal peripheral T-cell lymphomas: diagnosis and therapeutic considerations. Rev Bras Hematol Hemoter 37: 277-284. [Crossref]

9. Foss FM, Zinzani PL, Vose JM, Gascoyne RD, Rosen ST, et al. (2011) Peripheral T-cell lymphoma. Blood 117: 6756-6767. [Crossref]

10. Khong PL, Pang CB, Liang R, Kwong YL, Au WY (2008) Fluorine-18 fluorodeoxyglucose positron emission tomography in mature T-cell and natural killer cell malignancies. Ann Hematol 87: 613-621. [Crossref]

11. Kako S, Izutsu K, Ota Y, Minatani Y, Sugaya M, et al. (2007) FDG-PET in T-cell and NK-cell neoplasms. Ann Oncol 18: 1685-1690. [Crossref]

12. Zhou X, Lu K, Geng L, Li X, Jiang Y, et al. (2014) Utility of PET/CT in the diagnosis and staging of extranodal natural killer/T-cell lymphoma: a systematic review and meta-analysis. Medicine (Baltimore) 93: e258. [Crossref]

13. Casulo C, Schöder H, Feeney J, Lim R, Maragulia J, et al. (2013) 18F-fluorodeoxyglucose positron emission tomography in the staging and prognosis of T cell lymphoma. Leuk lymphoma 54: 2163-2167. [Crossref]

14. Weisenburger DD, Savage KJ, Harris NL, Gascoyne RD, Jaffe ES, et al. (2011) Peripheral T-cell lymphoma, not otherwise specified: a report of 340 cases from the International Peripheral T-cell Lymphoma Project. Blood 117: 3402-3408. [Crossref]

15. Rock J, Bloomston M, Lozanski G, Frankel WL (2012) The Spectrum of Hematologic Malignancies Involving the Pancreas. Am J Clin Pathol 137: 414-422. [Crossref]

16. Paes FM, Kalkanis DG, Sideras PA, Serafini AN (2010) FDG PET/CT of Extranodal Involvement in Non-Hodgkin Lymphoma and Hodgkin Disease. Radiographics 30: 269-291. [Crossref]

17. Moskowitz AJ, Lunning MA, Horwitz SM (2014) How I treat the peripheral T-cell lymphomas. Blood 123: 2636-2644. [Crossref]

Copyright: C2018 Demirel BB. This is an open-access article distributed under the terms of the Creative Commons Attribution License, which permits unrestricted use, distribution, and reproduction in any medium, provided the original author and source are credited. 